\title{
Specific clinical problem areas
}

\author{
J. F. McCord, ' and A. A. Grant, ${ }^{2}$
}

\section{In this final article of the series, the clinical and technical aspects of a range of similar forms of immediate prosthesis are discussed. Similarly, copy denture and reline/rebase procedures are detailed.}

$\mathrm{I}$ $\mathrm{n}$ this section, specific clinical problem areas, which involve aspects over and above conventional complete dentures, will be discussed. The six areas to be discussed are:

- Conventional immediate complete dentures

- Copy (template) dentures

- Relines and rebases

- Overdentures (complete)

- Implant-retained/supported complete dentures

- Combination syndrome.

In addition to having to satisfy prosthodontic norms for conventional complete dentures, all six areas require distinct planning procedures, which relate to both technical and clinical procedures, yet they tend to share common problems, particularly with regards to retention and stability of complete dentures. The six categories are summarised and readers are referred to standard textbooks for more comprehensive descriptions.

\section{Conventional immediate complete dentures}

According to Nimmo and Winkler, an immediate denture may be defined as 'a complete or removable partial denture constructed for insertion immediately following the removal of natural teeth.' ${ }^{1}$ Such dentures were once provided on a regular basis in dental practice, especially in the post World War II era. For a variety of reasons, one of which is improved dental health education, this treatment regime is now less regularly provided.

In the interests of simplicity, and to avoid repetition for the remainder of this chapter, the term immediate denture will be intended to mean an immediate complete denture.

In theory, immediate dentures may be defined as interim or conventional. In the former, an existing (partial) prosthesis is converted into a complete denture. In the latter, conventional wisdom recommends that posterior teeth distal to the first premolar teeth are extracted, the ridges allowed to heal for 2-3 months and the anterior teeth subsequently extracted and a conventional immediate denture inserted.

Table 1 lists the potential categorisation of immediate dentures and also of overdentures. There are obvious similarities between the two from planning and technological points of view but the latter offers greater patient benefits (vide infra).

Transitional immediate complete dentures In this category, a patient who is currently wearing a satisfactory removable partial denture is rendered edentulous and the teeth to be replaced are added to the denture. Additional base material, to effect maximal coverage of the denture-bearing area, is also provided. This is the philosophy behind training dentures and is the rationale behind the prescription of, eg Kennedy I type dentures in older patients for whom the prognosis of the remaining teeth is poor. After a period of time to enable, it is hoped, neuromuscular control of the training denture, an impression is taken with the training denture in situ. The resultant master cast is then modified by removal of the remaining teeth (see conventional immediate complete dentures) and the transitional denture processed. Figures 1-3 show the clinical stages in the transformation of the partial denture to the transitional complete immediate denture.

Conventional immediate complete dentures Although a range of clinical scenarios are possible, the most common clinical situation, and the one to be described is where the posterior teeth have been extracted and the anterior teeth remain. There is much merit in retaining, if possible, the four first premolar teeth to provide a reasonable and unambiguous occlusal stop in retruded contact position (RCP), and this provides an acceptable assessment of occlusal vertical dimension (OVD). The technique described here may be used if the premolar teeth are present or not.

\section{Stage 1}

The teeth to be removed are assessed clinically and radiographically, and an assessment of the levels of the alveolar bone made. Primary impressions are made using, eg a combination of impression compound and irreversible hydrocolloid (Fig. 4).

NB Although trays do exist for partially-dentate patients, we recommend, nevertheless, the combination of a viscous material (for the sad- 


\section{PRACTICE prosthetics}

\begin{tabular}{|c|c|c|c|}
\hline Table 1 & \multicolumn{3}{|c|}{ Theoretical categories of immediate dentures and overdentures } \\
\hline $\begin{array}{l}\text { Type of } \\
\text { denture }\end{array}$ & Transitional & Immediate & Definitive \\
\hline $\begin{array}{l}\text { Conventional } \\
\text { immediate }\end{array}$ & $\begin{array}{l}\text { - Previous partial denture used and } \\
\text { converted to a complete denture. } \\
\text { - After an appropriate period, a } \\
\text { conventional replacement } \\
\text { (definitive) denture is made. }\end{array}$ & $\begin{array}{l}\text { - Posterior teeth removed, and after a set } \\
\text { time, the remaining teeth are extracted } \\
\text { and the complete immediate denture } \\
\text { is inserted. } \\
\text { - After an appropriate period, a } \\
\text { conventional replacement (definitive) } \\
\text { denture is made. }\end{array}$ & $\begin{array}{l}\text { - Not an accurate description here, as, } \\
\text { by definition, conventional immediate } \\
\text { dentures cease to be so on insertion, } \\
\text { owing to the nature of extractions and } \\
\text { subsequent resorptive processes. }\end{array}$ \\
\hline Overdenture & $\begin{array}{l}\text { - Previous partial denture used } \\
\text { and converted to a complete } \\
\text { denture. } \\
\text { - After an appropriate period, a } \\
\text { definitive replacement overdenture } \\
\text { is made. }\end{array}$ & $\begin{array}{l}\text { - Posterior teeth removed, and after a } \\
\text { set time, the teeth selected as } \\
\text { overdenture abutments are prepared } \\
\text { to receive the overdenture and the } \\
\text { complete immediate denture is } \\
\text { inserted. } \\
\text { - After an appropriate period, a } \\
\text { definitive replacement overdenture } \\
\text { is made }\end{array}$ & $\begin{array}{l}\text { - In this category, the dentures receive } \\
\text { some or most of their support and perhaps } \\
\text { retention and some stability via either } \\
\text { i. abutment roots }+/- \text { precision } \\
\text { attachments } \\
\text { ii. implants + precision attachments }\end{array}$ \\
\hline
\end{tabular}

dle areas) and a less viscous impression material for the areas where teeth are retained, as the philosophies for primary impressions outlined in Part 4 apply here.

It is also worth mentioning here that patients ought to be informed of the fact that immediate dentures represent a useful solution to the advent of edentulousness. These dentures may require several chairside relines during the first 3 months after insertion of the immediate denture(s) and will require to be replaced some time after that (although, some patients have coped with immediate dentures for many years). The medico-legal implications of this important piece of information should not be overlooked and Figure 5 shows a patient information leaflet regarding complete dentures.

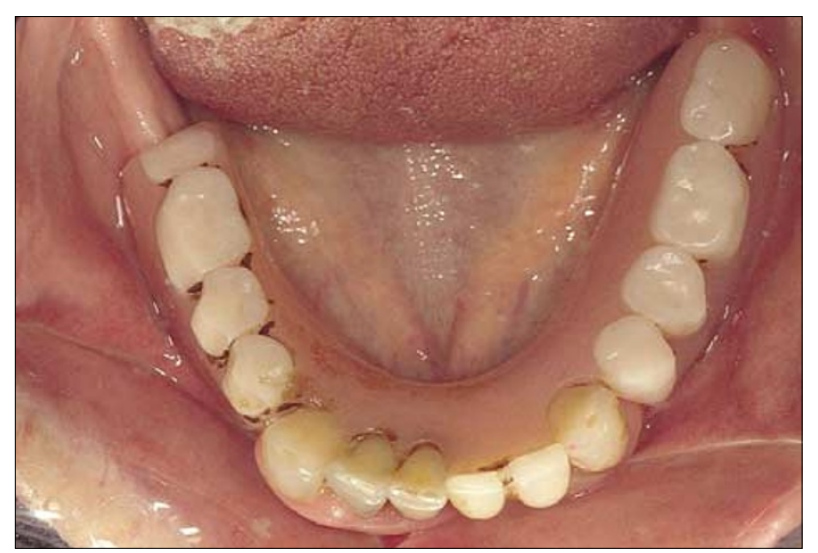

Fig. I Occlusal view of remaining teeth and present lower partial denture

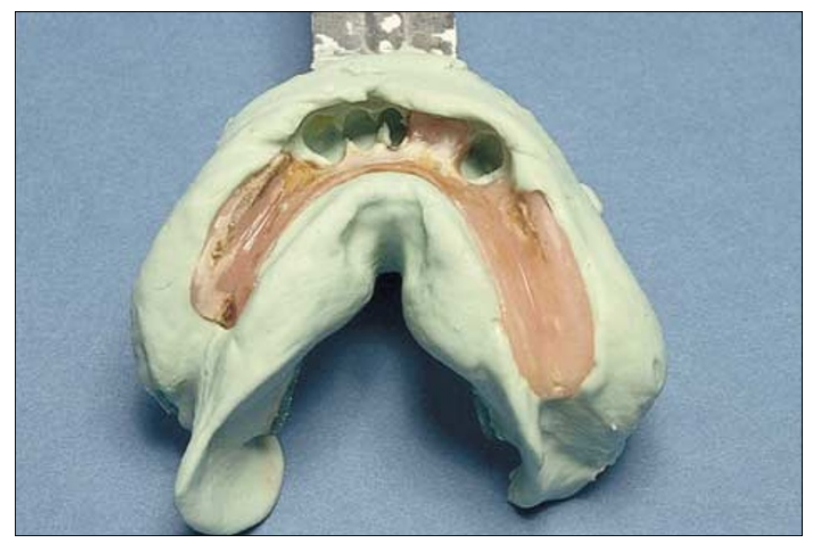

Fig. 3 Pick up impression showing current denture and remaining teeth. It is a simple matter for the technician to add the remaining teeth to the present denture

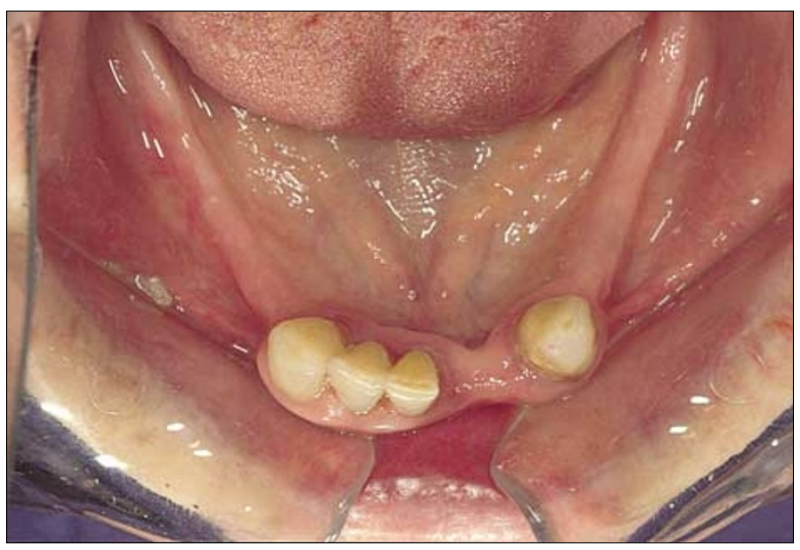

Fig. 2 Occlusal view of remaining teeth and edentulous saddles

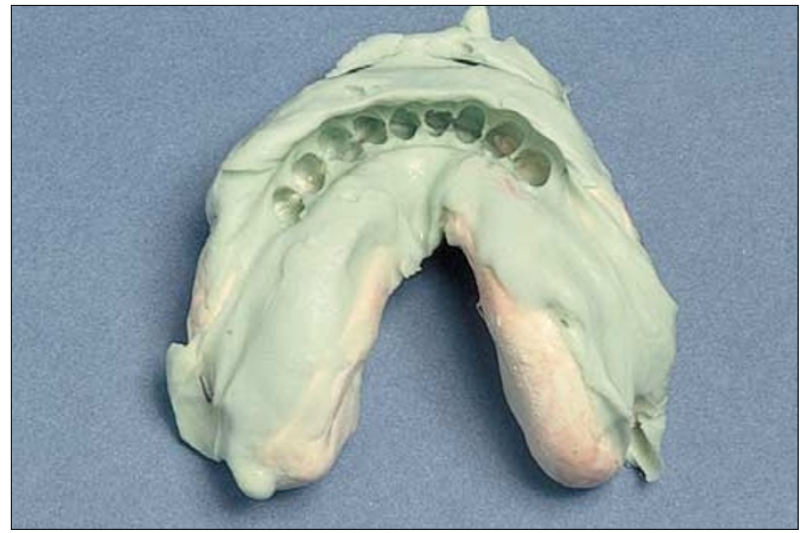

Fig. 4 Stock tray modified with impression compound in the saddle area and overall irreversible hydrocolloid impression material 


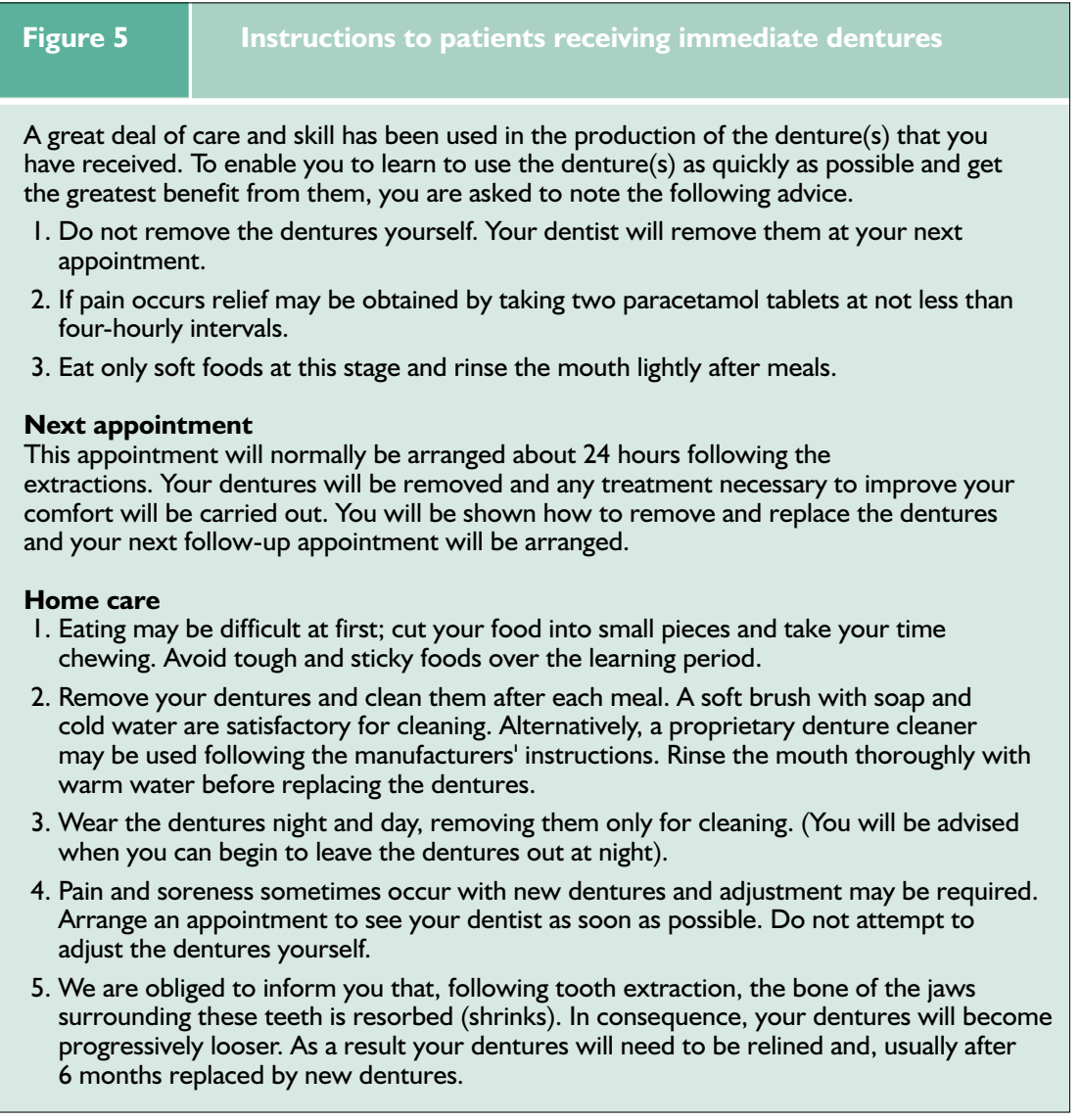

Fig. 5 Patient information leaflet on immediate dentures

\section{Stage 2}

A definitive impression is made. It should be emphasised that time should be taken to ensure that the peripheries are appropriately extended. Patients who have never worn complete dentures previously will have to endure enough adaptational problems without having to cope with instability as a consequence of over-extension. Again, the clinician should specify to the technician the amount of spacing required, according to the type of impression material to be used.

\section{Stage 3}

Registration of intermaxillary relations. As with conventional complete dentures, vertical, antero-posterior and coronal relations need to be recorded and record rims (Fig. 6) will help

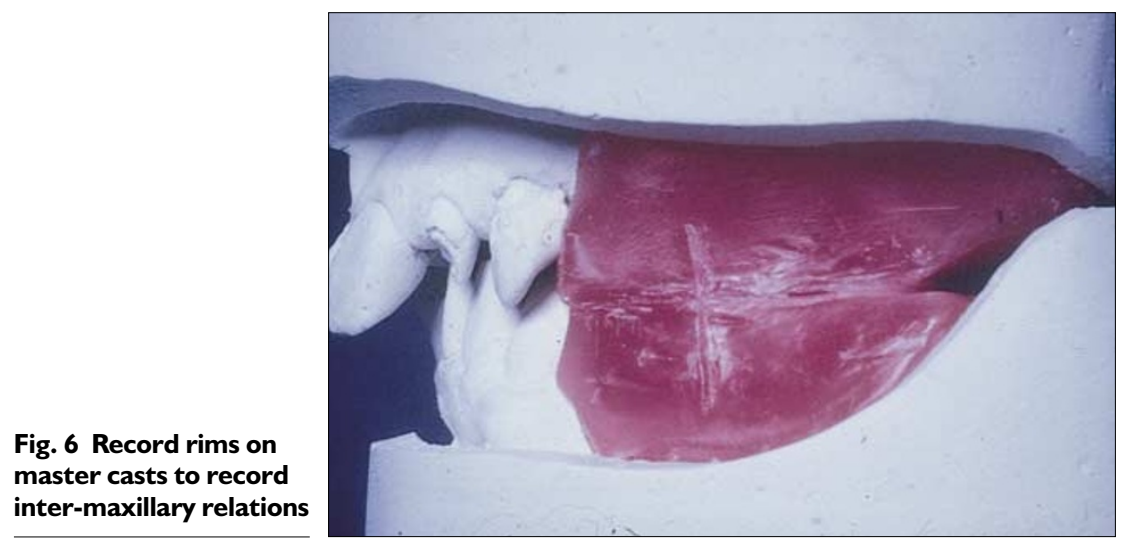

the clinician to record these relations. It may be possible to use the remaining anterior teeth as a means of selecting the mould and shade of the teeth for the immediate denture; in some cases, the remaining teeth may not lend themselves to copying and a conventional method may be used to assess tooth selection (vide supra).

Stage 4

The three-dimensional inter-maxillary relations are confirmed at the trial denture stage as is the shade and form of the teeth. The information above, plus details of pocket depth enable the technician to determine where to position the necks of the replacement teeth. Equally, the clinician should decide whether the immediate denture has no flange (open-faced) a short flange (ridge-lapped) or whether a full flange can be accommodated. The presence of large undercuts may rule out the latter (Figs 7 and 8). In such cases, and where there is a need to attempt to restore a semblance of the interdental papillae, the flange may be taken to the bulbosity of the alveolar undercut using a short flange. Readers are referred to textbooks of prosthodontics for details of the technical procedures.

The dentures are then completed ready for insertion following an effective cross-infection regime prior to the required clinical procedures.

After the insertion of the immediate dentures, the patient is given instructions on the care of their dentures (see Fig. 5) and reviewed after 24 hours and then weekly, according to patient need until the clinician prescribes a reline. This may be a conventional type of reline or a 'chairside' reline using an auto-curing material.

\section{Copy (template) dentures}

Although impression techniques relating to this form of treatment were outlined in Part 4, we feel that it is appropriate to elaborate on the philosophy of template dentures. Over 30 years ago, Brill recognised that some patients, particularly elderly patients, had problems adapting to the (new/altered) form of replacement dentures. ${ }^{3}$ He argued that retention of the form of the polished surfaces of the dentures and relining/rebasing of the impression surfaces (denture bases) would enable the dentist to provide replacement dentures to which (older) patients might adapt more easily. This philosophy led to the birth of the 'copy' denture technique. If all surfaces of the complete denture were being replicated, this would indeed be a 'copy' denture. If only the polished surface is being replicated, however, then we would argue that the technique should be considered a template technique, as the denture bases and the occlusal surfaces are altered, only the polished surface is 'copied'. A variety of techniques was referred to 
in Part 4, and practitioners should use the one that works best for them.

There is no doubt that the template technique is a sensible and effective treatment strategy for older patients, or those patients who because of neurological impairment are unlikely to develop good muscular adaptation to conventional complete dentures.

The clinical stages for template dentures are;

- At the first visit, after appropriate history recording and diagnosis, prior to templating, primary impressions may be made. As was described in Part 4, the existing dentures are replicated. Given the stability of polyvinylsiloxane putty systems, we would recommend the techniques whereby this is used, especially for practitioners who do not have casting services on the premises.

- At a second clinical visit, impressions are made within the replicated dentures; this serves effectively as a relining/rebasing to improve the fit of the denture base to the denture-bearing tissues. The occlusal surfaces are then modified to a new OVD and RCP if desired.

- At the third visit, the wax trial denture is assessed and if the dentures are perceived to be satisfactory by both the clinician and the patient, the dentures are sent to the laboratory to be processed conventionally.

This technique has been shown to result in successful resolution for those clinical cases (vide supra) in which conventional prosthodontics might not have worked. Although the concept of template dentures is philosophically simple, it nevertheless requires that the clinician exercises appropriate clinical skill and judgement.

Three areas of caution, in particular are worthy of consideration.

- Ensure, in the older patient especially, that the OVD is carefully selected. This problem has already been referred to in Part 6.

- None of the currently described techniques adequately caters for problems of support (eg displaceable upper ridge) and modifications of impression techniques may be necessary to overcome these problems.

- This technique requires that the technical support is proficient. If the replication of the denture form is not thorough, the outcome of the treatment may be jeopardised.

\section{Relines and rebases}

Although one technique for a 'reline' impression was described in Part 4, this merely describes how to do it. We feel that this approach, while appropriate to a chapter describing impression techniques, requires elaboration, hence we have included some comments here on the basic principles of relining/rebasing, as we feel that this procedure is often mistakenly assumed to be a 'simple' procedure that tends to be performed poorly.

Residual ridge resorption under denture bases is an inevitable occurrence and all patients ought to be informed of this. As was described earlier, this resorption may be pre-

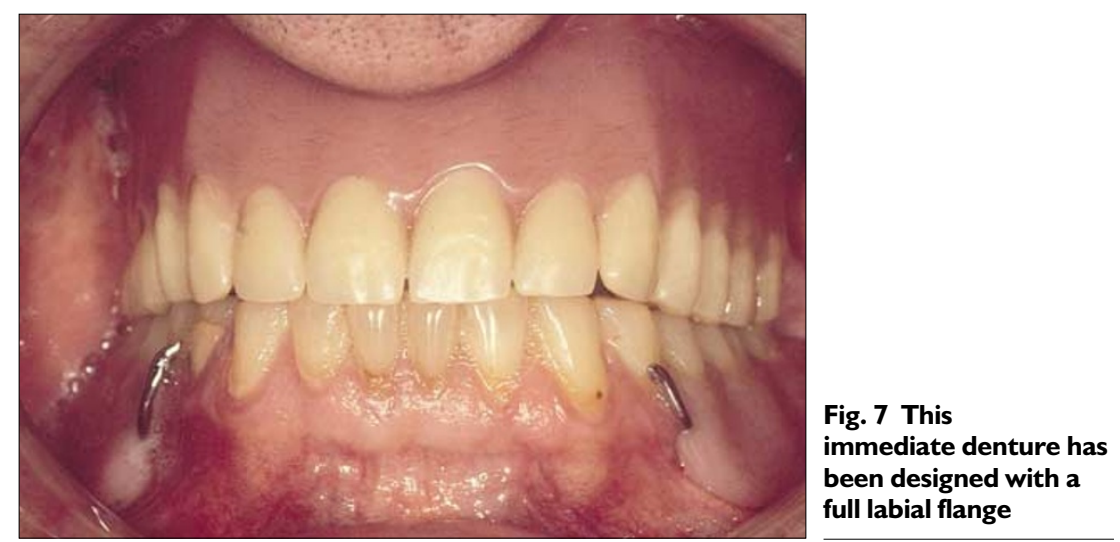

dicted to occur rapidly over the first 3 months post-extraction then slow down, although there will inevitably be great variation among patients. Dentists, we feel, should be mindful of the need to maintain the adaptation of the denture bases to the selected areas of the denturebearing area.

In order to compensate for residual ridge resorption, the impression surfaces of the dentures may on occasion be modified; the two processes whereby this may be carried out are termed relining and rebasing.

According to the Glossary of Prosthodontic Terms, relining describes the procedures used to resurface the tissue (impression) surface of the denture with new base material, ${ }^{2}$ thus producing an accurate adaptation to the denture foundation area.

In the same document, a rebase is described as the laboratory process of replacing the entire denture base of an existing prosthesis.

In essence, the process of relining is carried out on mandibular complete dentures and the process of rebasing is carried out on maxillary complete dentures, although many practitioners use the term reline to mean both.

The indications and contra-indications for relining/rebasing are listed in Table 2.

Further factors to be taken into considerations for relining and rebasing are:

- The OVD should be acceptable (where minimal freeway space (FWS) is present, this could induce further denture-wearing problems).

- There should be occlusal balance in RCP, or should be easily achievable if not present.

- The dentures are adequately extended, or may be easily rendered so via a chairside reline material or tracing compound, prior 
Fig. 8 Owing to an obvious labial undercut, there has been no attempt to place a full flange and an open appearance has been created.

NB Socketing is not recommended as it encourages an inappropriate appearance posthealing to the recording of the impression - there is little point in relining a denture that does not satisfy prosthodontic norms.

The clinical and technical procedures for replacement of the denture base of complete dentures are relatively complicated and require clinical competence - if denture bases are severely under-extended, unattainable balanced occlusion exists in RCP and a gross loss in OVD has occurred, practitioners are advised to prescribe replacement dentures.

\section{Overdentures}

According to Basker et al., overdentures are prostheses constructed to gain support and retention from retained roots (or dental implants). ${ }^{4}$ In this section, the term overdentures is intended to mean complete denture overdentures.

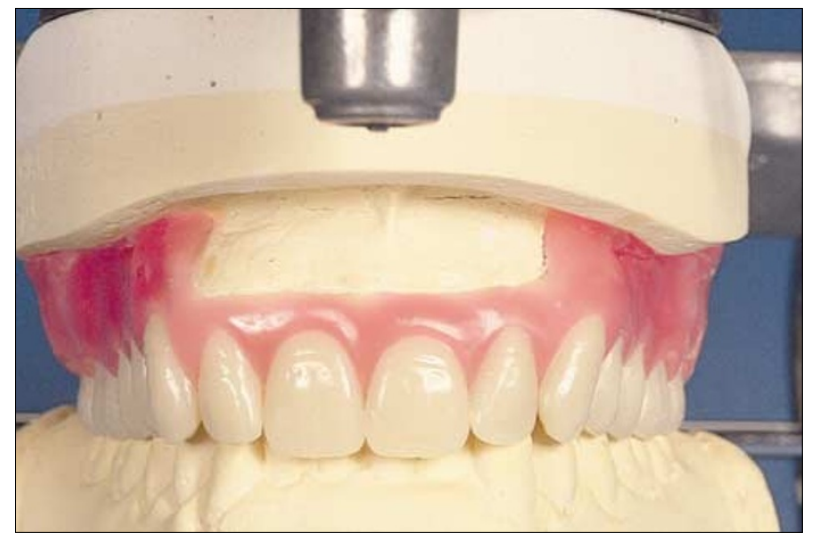

In essence, the retention of roots to support/retain an overdenture has been shown to reduce residual ridge resorption, improve stability and to retain proprioception. ${ }^{3}$ For a more detailed description of overdentures, readers are recommended to standard textbooks on the subject. ${ }^{4,5}$

As is described in Table 1, overdentures may be classified as being one of three classes, transitional, immediate and definitive.
Transitional overdentures

As with the immediate denture category, a partial denture worn by the patient is modified by addition of teeth; the planned retention of two or more roots facilitates adaptation to complete dentures, in addition to reducing ridge resorption. In all other respects, the clinical and laboratory stages are similar to those of transitional immediate dentures. In this technique, the teeth are reduced in height (to the level of the gingival margins) at the time of the insertion of the denture. To guard against rocking of the denture on insertion, the clinician is advised to reduce the teeth on the master cast above the gingival margins. This will ensure that there will be a small space between the overdenture abutment teeth and the denture; this space may be filled in by a chairside reline material to ensure stability of the transitional immediate denture.

\section{Immediate overdentures}

The clinical and technical stages of this type of overdenture are essentially similar to that of immediate overdentures. The clinical differences are clearly that a planned number of roots are retained and, post-decoronation, the clinician has to decide how best to seal-off endodontic access cavities (if endodontic procedures have been carried out) or of dentinal tubules if elective endodontics has not been performed.

It is not established practice to place precision attachments in immediate overdentures.

A second point is that, in these situations, hard tissue undercuts tend to contra-indicate full labial flanges and most immediate overdentures tend to have a ridge-lapped appearance (Fig. 8). In these cases, there is no real flange but the acrylic of the denture base is extended up to the ridge undercut. In addition to improving the appearance of the denture by incorporating interdental papillae, this technique helps mask some resultant ridge resorption.

\begin{tabular}{|l|l|}
\hline Table 2 & \\
\hline Indications & Contra-indications \\
\hline $\begin{array}{l}\text { - } 3-6 \text { months post insertion of immediate } \\
\text { complete dentures. }\end{array}$ & $\begin{array}{l}\text { When an excessive amount of resorption has } \\
\text { occurred. }\end{array}$ \\
$\begin{array}{l}\text { - When adaptation of denture bases to the } \\
\text { tissues of the denture-bearing areas is poor. }\end{array}$ & $\begin{array}{l}\text { When the underlying tissue is inflamed and/or } \\
\text { hypertrophic or hyperplastic. }\end{array}$ \\
$\begin{array}{l}\text { - When, for medical or social reasons the } \\
\text { patient is unable to attend the required number } \\
\text { of visits for replacement dentures and no } \\
\text { contra-indications apply. }\end{array}$ & $\begin{array}{l}\text { When the patient exhibits symptoms suggestive of } \\
\text { the problems. Accurate diagnosis and resolution of }\end{array}$ \\
$\begin{array}{l}\text { - When the patient is unable to afford } \\
\text { replacement complete dentures and no } \\
\text { contra-indications apply. }\end{array}$ & $\begin{array}{l}\text { - When the dentures have induced a speech problem. } \\
\text { - When the appearance of the dentures is } \\
\text { unsatisfactory to the patient. }\end{array}$ \\
& $\begin{array}{l}\text { When the intermaxillary relationships are } \\
\text { unsatisfactory. }\end{array}$ \\
\hline
\end{tabular}


To avoid embarrassment of a social nature to the patients (and of a professional nature to clinicians) it can be reasonable practice to use denture fixative at the time of insertion of this overdenture type. This is especially valid if the patient has never worn a denture previously, as the (soft) tissues of the denturebearing area may take some time to be displaced.

\section{Definitive overdentures}

At a selected period post-extraction and decoronation and insertion of either a transitional overdenture or an immediate overdenture, a replacement overdenture may be planned. This replacement denture may be a straight-forward replacement complete denture which happens to be an overdenture; in this case, conventional techniques would suffice.

If, however, there is a need to improve retention, the clinician may decide to use precision attachments. The two most common precision attachments used for overdentures are studs (Fig. 9) and bar assemblies (Fig. 10). The reader is referred to a textbook on overdentures on indications and contra-indications here, eg if a bar is selected, then it tends to assume that the roots are approximately parallel.

When the clinician has determined which type of precision attachment is appropriate for the patient, the treatment sequence followed is as follows:

- Stage 1. Primary impressions recorded as for the conventional denture technique. The technician should be informed of the decision to prescribe precision attachments and the case planned with the laboratory before proceeding further.

- Stage 2. If the abutment teeth have been endodontically-treated, then the root canals of selected teeth (usually canine teeth) are prepared with reamers matched to impression posts to give parallel-sided threaded posts. One such system is illustrated in Figure 11. Definitive impressions are recorded, again with the same attention to detail for peripheral seal as per conventional dentures.

- Stage 3. The appearance of the upper denture, intermaxillary relations and selection of tooth moulds and shades are carried out as for conventional dentures.

- Stage 4. In addition to the trial insertion(s) for the denture(s), the clinician should verify the accuracy of fit of the precision attachments. When precision attachments and trial denture are deemed to be satisfactory, the overdentures may be processed.

- Stage 5. As the retention of teeth does significantly enhance function and retention of lower dentures particularly, extreme caution is advised to ensure that the occlusal schemes of the dentures are in harmony with

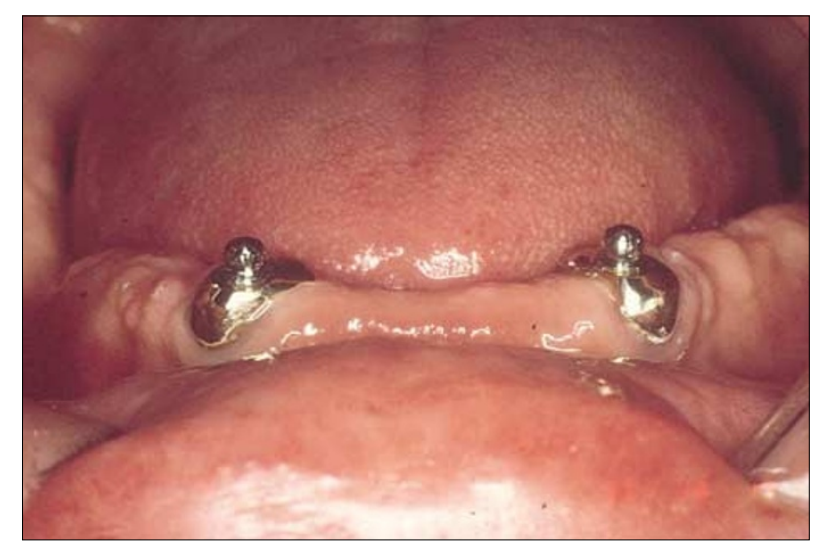

Fig. 9 Studs used to retain lower complete overdenture

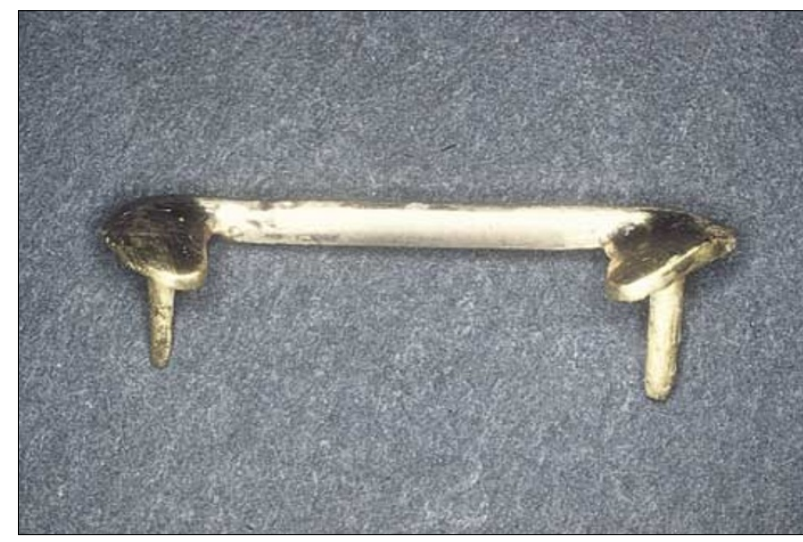

Fig. I0 A bar assembly used to retain a complete lower overdenture

mandibular movements, or (upper) denture instability may well result.

- Stage 6. As with all other denture types, review visits and recall visits are necessary.

Patients should be made aware of the need to maintain good oral hygiene around abutments. They should also be informed that maintenance is required for the precision attachments; the effects of wear and tear on the precision attachments means that tightening and/or replacement will be inevitable at some time.

\section{Implant-retained complete dentures}

An implant is a device or substance that is placed or implanted in the body for the purpose of restoring lost or deficient function and/or the replacement of deficient tissue. A dental implant is implanted into or onto the tissues of

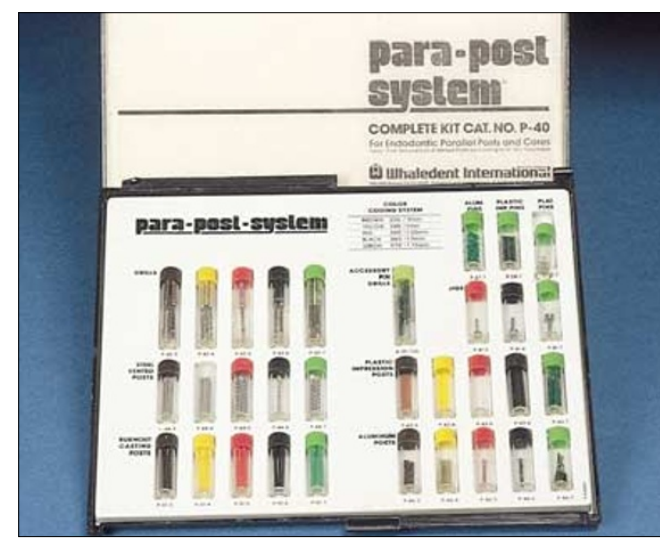

Fig. I I Para-post system which has reamers, which match impression posts 


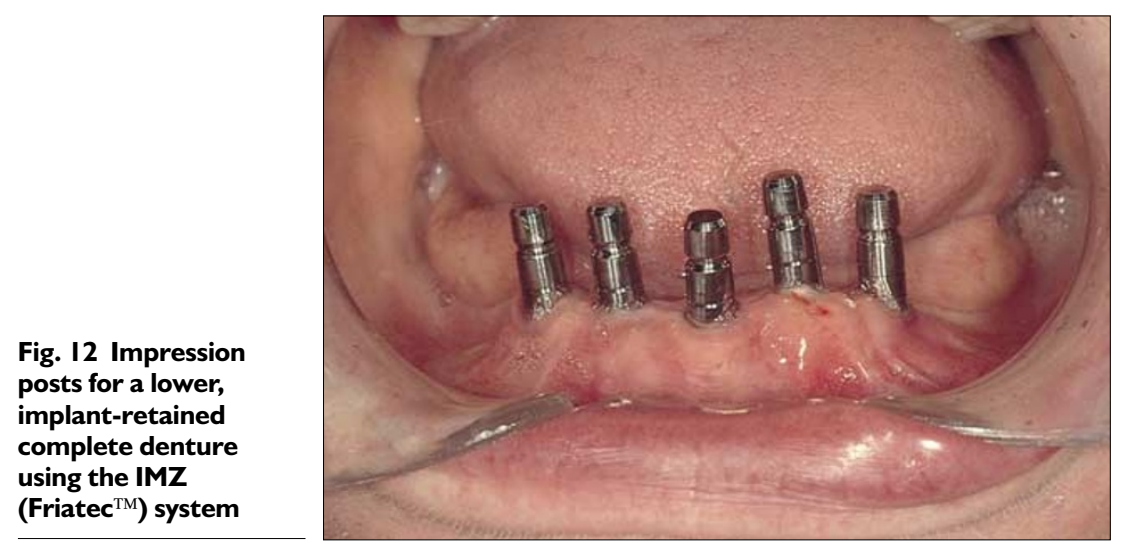

Fig. 13

Impression posts for a lower, implantretained complete denture using the Nobel-Biocare ${ }^{\mathrm{TM}}$ system

Fig. I4 Intra-oral view of implant-supported bar assembly

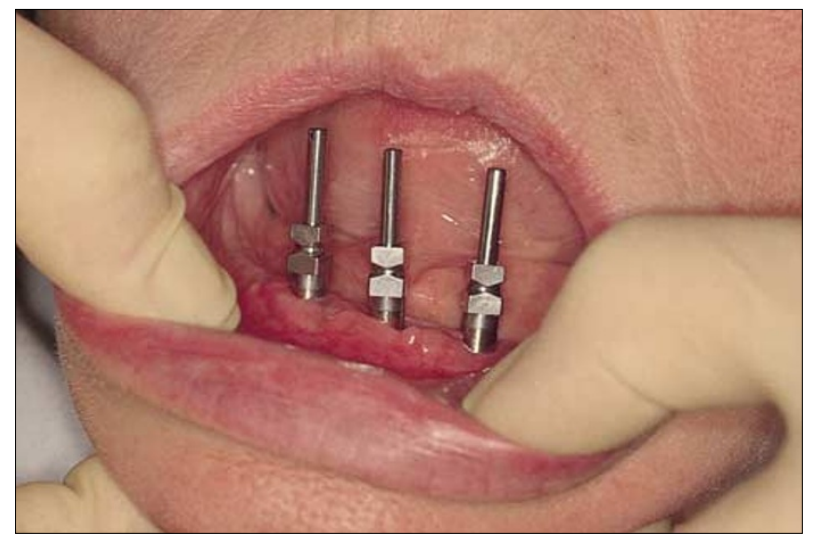

the jaws with the object of providing anchorage for a fixed or removable prosthesis, or for the augmentation or regeneration of deficient tissues. Clearly with such a general definition, a range of implant materials and implant types may be used. For the interests of this chapter, the implant material discussed is titanium (or alloys of titanium) and the type of implant referred to is the endosseous implant. Examples shown demonstrate two types (Nobel-Biocare ${ }^{\mathrm{TM}}$ and Friatec $^{\mathrm{TM}}$ ) and these reflect the clinical experience and preference of the authors.

Substantial data are available to indicate the very real functional and psychological advantages of restoring edentulous jaws with dental implants, ${ }^{6,7}$ and there is no doubt that this treatment modality is practised universally by specialist prosthodontists and general dental practitioners. We would recommend that clini-

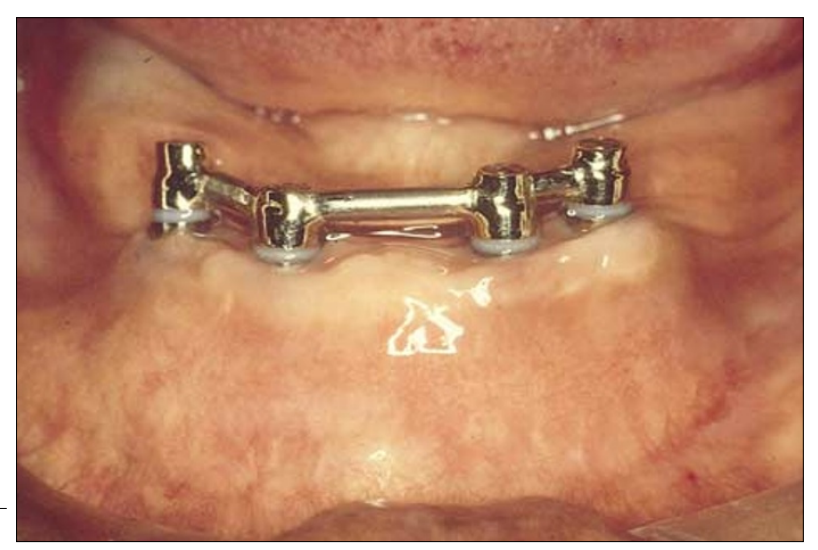

cians undertaking such treatments undergo sufficient clinical training to comprehend the surgical and prosthodontic philosophies inherent in well-established and creditable implant systems.

We would further contend that the restorative clinician is the orchestral leader of implant therapy as they should be involved with treatment planning at the onset of treatment, establishing the form of the surgical template, prescribing the intermediate and definitive prostheses and overseeing the maintenance of the prosthesis/es.

The prosthodontic stages inherent in implantretained (complete) denture therapy, in addition to treatment planning stages are as follows:

- Stage 1. The clinician proceeds with the case as for a conventional denture and, at the trial denture stage, when satisfied with the form and function of the trial dentures, arranges the surgical stent(s) required. One such stent is illustrated in Fig. 3 of Part 8. The surgeon uses this stent to help position the implants.

- Stage 2. Post-insertion of the implants, the patient is advised to refrain from wearing their denture for 1 week. Thereafter, successive resilient linings will be required to reduce trauma to the tissues overlying the implants. Relief will also be required over the site of the implants to reduce the potential for loading of the implants during this period when, it is hoped, osseo-integration is occurring.

- Stage 3. After the implants have been uncovered and healing caps placed on the permucosal abutments, impressions are taken. Figures 12 and 13 indicate two systems and their different (although fundamentally similar) impression techniques for implantretained complete dentures. In the particular case shown in Figure 12, the central implant was not utilised and subsequently covered up to allow room for the bar assembly.

In essence, the stages following this are similar to those described above for definitive overdentures, with the exception that the abutments used are screwed in place.

Figure 14 is an intra-oral view of an implantsupported bar assembly in situ.

As with overdentures, the need to include maintenance visits should always be emphasised to the patient.

\section{Combination syndrome}

Reference has been made previously to the difficulties encountered by having to provide a replacement complete denture in one arch while the opposing arch contains a natural (or essentially natural) dentition; this challenging clinical combination has been termed the combination syndrome. Two types exist: edentulous maxilla 
opposed by natural dentition and edentulous mandible opposed by natural dentition.

Edentulous maxilla opposed by a natural dentition in the mandibular arch.

In this situation, the displacing forces on the upper denture resulting from mandibular movements have to be harnessed and a variety of ways of maximising the retentive forces and reducing the displacing forces must be used.

The retaining forces are maximised by ensuring that a peripheral seal is present and this has been described in an earlier chapter.

Displacing forces are reduced by co-ordinating the maxillary teeth and maxillary plane of occlusion to mandibular movement. These are achieved via one of the following ways:

- Using a facebow to transfer the plane of the upper arch to the condylar axis.

- Using a central-bearing screw to create an arrowhead (Gothic-arch) tracing.

- Setting the articulator condylar angles to accord to the border tracings on the arrowhead tracing.

- Establish, carefully, at trial insertion, that RCP is reproducible.

- That the technician 'mills' the occlusion to suit the patient. This will inevitably be necessary, as (denture tooth) cuspal inclines will be unlikely to equal those of the patient. This should not be carried out without consideration of aesthetic and functional demands of the patient and should be carried out in advance of the recording of definitive impressions of the mandibular arc.

- On occasion, the clinician may need to use the patient to 'mill-in' the occlusion in the chair. A technique sometimes used by the authors is to make a paste of carborundum powder and toothpaste and to ask the patient to trace out the border movements with the denture in situ and with the teeth in occlusion.

- In our clinical experience, there has inevitably been a need to review the patient after 3 days and to refine the cuspal anatomy of the maxillary denture teeth.

- Clinicians should be aware of the need to maintain and even replace dentures in these conditions, hence patients should also be so informed at the onset of treatment.

As with most complete denture problems, patient co-operation is essential if success is to be achieved.
Edentulous mandible opposed by a natural dentition in the maxillary arch.

This clinical problem is even more difficult to treat than the former and although identical techniques are recommended in this scenario, success will be more problematic. Even with sound prosthodontic impression techniques, displacing forces will inevitably overwhelm retaining forces of the mandibular denture and only immense physiological control of the denture will create stability. In this clinical situation, implant-retained dentures are in a class of their own as a preferred treatment modality.

Although other problematic clinical situations exist, we have attempted to cover the principal situations which may be encountered in daily general dental practice and this section, in addition to Part 10 gives, it is hoped, an insight how to identify and treat common prosthodontic problems.

\section{Helpful Hints}

I. For any form of immediate denture, always inform first-time complete denture-wearers of: a: the problems associated with managing complete dentures and b: the inevitable residual ridge resorption and its sequelae.

2. Immediate complete immediate dentures or complete overdentures the clinician should ensure that the essential principles of complete denture prosthodontics are adhered to.

3. Where complete upper overdentures are concerned, tissue displacement (and associated tissue fluid displacement) usually does not occur at the time of insertion of the denture and a denture adhesive may be required over the first 24-48 hours. The patient should be advised (of this possible transient retentive aid) before the insertion-visit to avoid the patient developing a negative stereotype towards the dentures and/or the clinician.

4. Where precision attachments are used for conventional overdentures or implant-retained overdentures, the clinician should remember that they occupy space and may be bulky. The clinician is also advised to consult with his/her technician, at the treatment planning stage, as to the technical feasibility of each case.
This series is available as a BDJ book - A Clinical Guide to Complete Denture Prosthetics by Professor J F McCord and $\operatorname{Dr} A$ A Grant (ISBN 090458864 5, price 629.95$)$ This can be purchased from Macmillan Direct, Brunel Road, Houndmills, Basingstoke, Hants RG21 6XS

Tel: 01256302699
1 Nimmo A, Winkler, S In Winkler S (ed). Essentials of Complete Denture Prosthodontics (2nd. edn). St. Louis: Mosby, 1988 pp 361-374.

2 Brill N. Factors in the mechanism of full denture retention. Dent Pract Dent Rec 1967, 18: 9-19.

3 The Academy of Prosthodontics. The Glossary of Prosthodontic Terms, (6th edn). J Prosthet Dent 1994; 71 : 41-116.

4 Basker R M, Harrison A, Ralph J P, Watson C. Overdentures in general dental practice (3rd edn). London, BDJ pp 1-9, 1993.

5 Brewer A A, Morrow R M. Overdentures (2nd edn). St. Louis, Mosby, 1980.

6 McCord J F, Grant A A, Quayle A A. Treatment options for the edentulous mandible. Eur J Prosthodont Rest Dent 1992; 1: 19-23.

7 Blomberg S. In Branemark P I, Zarb G A, Carlsson G E (eds). TissueIntegrated Prostheses, Osseointegration in Clinical Dentistry 1985 , Chicago: Quintessence Publishing Co. Chapter 9, pp165-174. 